\title{
Analysis on Factors Affecting Farmers' Participating in the Chinese New Rural Social Endowment Insurance from the Ecological Perspective
}

\author{
Haobang Wu ${ }^{1}$, Li Wang ${ }^{1}$, Feng Yin ${ }^{2}$ \\ ${ }^{1}$ School of Political Science and Public Administration University of Electronic Science and Technology of China, Sichuan \\ Province, China \\ ${ }^{2}$ School of Computer Science and Technology Southwest University for Nationalities of China, Sichuan Province, China \\ vdepp@sina.com, yf_eagle@aliyun.com
}

\begin{abstract}
Since 2009, the new rural social endowment insurance system has gradually started the pilot in China. However, some farmers didn't get a high initiative to participate, which showed a serious impact on the promotion of the new system. This paper, based on the food chain theory, analyzes the various factors which influence farmers on participating in the new rural social endowment insurance, draws a conclusion about it and puts forward some proposals for the work of the government to promote the new rural social endowment insurance work smoothly and effectively and let the rural residents enjoy the beautiful results of the socialist development.

Index Terms - New rural social endowment insurance, Food chain, Factors, Proposals
\end{abstract}

\section{Introduction}

The Chinese new rural social endowment insurance is provided by the state as a public good, and is an important guarantee for rural residents to maintain their basic livelihoods in their later years. With the growing of the rural aging in this society, it is imperative to establish a sound rural endowment insurance system. Therefore, the State Council decided that the new rural social endowment insurance pilot work would be made from 2009, and discovered a new rural social endowment insurance system in line with the suitable rural status according to the principles of "basic security, wide coverage, flexibility, sustainability"[1]. In 2009, the first pilot was applied to the $10 \%$ of the counties in China, and was gradually expanded to $40 \%$ in 2011 . In the pilot areas, some farmers participated in the new rural social endowment insurance inactively due to various factors, and it resulted directly in the low rate of enrollment in those areas, which not only affected the promotion work of the new system, but also made it difficult for the farmers to get effective protection for their basic livelihoods in their older lives. And such a path interacts closely as the food chain of the ecosystem. Therefore, the ecological theory should be applied to the new rural social endowment insurance, which not only helps to straighten out the causal relationship at all levels, but also helps to identify the source of the problems. It will be easy for the government to take appropriate measures to resolve these problems, so that the new rural social endowment insurance will truly become the "shock absorber" for the farmers to live a comfortable life, and the "safety valve" for the economic development in rural areas.

\section{Theoretical Basis}

\section{A. Ecological Theory}

Ecological theory is a branch of the science to study the interactions among the organisms and between organisms and their surrounding environments, and its purpose is to achieve the sustainable development between the environmental conservation and human development. Currently, the ecological theory has got a thorough development, and has been widely used in information, economic and management research. It also provides a new perspective for the social sciences. Population dynamics, niche theory, life-cycle theory are important theories in ecology. Therefore, the theory of the food chain can be adopted for research on the new rural social endowment insurance rates.

Food chain, also known as nutrient chain, and all creatures in the food chain have to intake the energy and nutrient from the outside in order to maintain their basic lives. This chain between various organisms formed by the energy and nutrients is called the food chain[2]. In the grasslands, the relationship among the grass - rabbit - fox; in the lakes, algae fish - big fish. In the food chain, nutrition and energy flow from left to right, and form a sequential transmission path, reflecting the material needs of the biological populations. Each link in the food chain is called trophic level. In the entire ecosystem, the primary producers in the starting point of the food chain, make the nutrition and energy and transfer them to the consumers in next level. Therefore, the primary producers can be called the first trophic level, a consumer in the first level is called the second trophic level, and so on. And in each food chain, the lower trophic levels are the nutrition and energy suppliers of the organisms in the higher trophic levels[3]. It is easy to find out that the primary trophic level plays a pivotal role in the food chain of the entire ecosystem .

\section{B. The Application of Food Chain Theory to the Analysis of Factors Affecting Farmers' Participation in the New Rural Social Endowment Insurance \\ The new rural social endowment insurance, as a very} important part in the social security system, is of crucial 
importance in stabilizing the rural social order, accelerating the construction of new countryside as well as building a harmonious socialist society. Therefore, the government has kept the rural endowment career as a top priority. From the first establishment of the rural social endowment insurance system in the 1990s, to the carrying out of the enactment "guidance on the new rural social endowment insurance pilot", it will be easily found out that the government has been exploring the endowment insurance exceedingly in rural areas. However, in today's society, the new rural social endowment insurance has encountered some problems and difficulties in the development process, making the system difficult to implement. Among which, the farmers' low participation rates are a typical phenomenon. Farmers do not accept nor participate in the rural endowment insurance, making it hard to conduct the new rural social endowment insurance pilot. It is difficult for farmers to see the effects of the implementation of the new system and the present defects and problems, and to see the tangible benefits brought by the new system to the rural elderly residents. Farmers involve in the insurance as the main subject, is related closely to the success of the new rural social endowment insurance. Thus, various factors affecting farmers' participation in the new rural endowment insurance should deserve the analysis and research from the scholars from domestic and abroad.

According to the trophic level of the food chain, it can also be considered as follows :

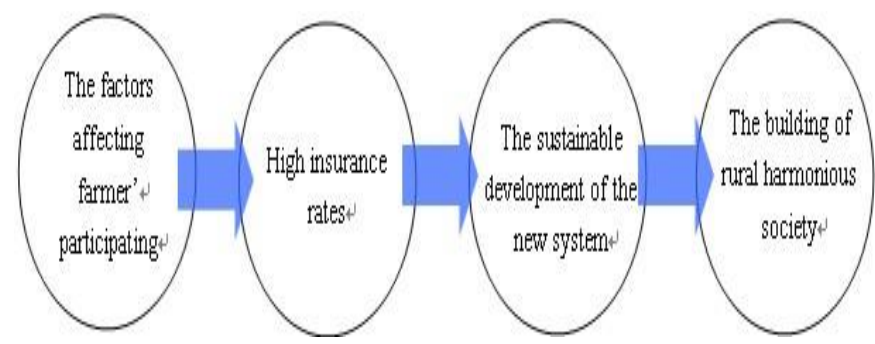

Fig. 1 The ecological chain of the new rural social endowment insurance.

There exist many multi-level reasons for the various factors which influences the farmers on participating in the new rural social endowment insurance. Those factors don't belong to the first trophic levels, so we call it the low trophic levels. If various factors in the low trophic levels can play a positive role in the rural endowment insurance, it will have an immeasurable impact on the new rural social endowment insurance rate; similarly, high insurance rates as the intermediate trophic level, can help us discover the effects as well as the shortcomings of the implementation of the new system, and thus improve it to greatly promote the smooth promotion and implementation of the new system, and to protect the sustainable development of the new rural social endowment insurance; finally, the new rural social endowment insurance as the senior nutrition level, has an extremely important role in improving the Chinese social security system, speeding up the development of rural areas and building a socialist harmonious society. It is obvious that this is a path with the constant transfer of energy and nutrients, and forms a ecological chain of energy and nutrients flows. Any offset adverse phenomena of the low trophic level in the ecological chain can cause instability for the whole ecological chain, so it is particularly necessary to analyze the factors affecting the peasants' participation in the new rural endowment insurance.

\section{The Low Trophic Level-Factors Affecting the Peasants' Participation in the New Rural Endowment Insurance}

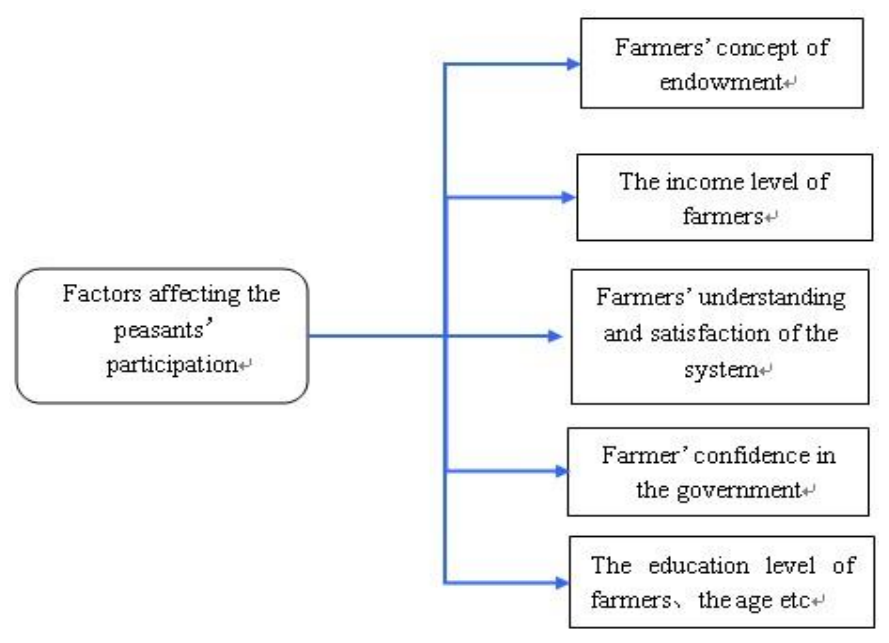

Fig. 2 The factors affecting the peasants' participation in the new rural endowment insurance.

\section{A. Farmers' concept of Endowment}

Farmers' endowment concept refers to the way that farmers expect to conduct the endowment insurance, which directly affects the willingness of the insured farmers. In China, there existed the traditional concept of "raising children for their old-age lives" since ancient times. Parents brought their children up when their children were very young, and when they were getting old, they would be taken care of by their children. It should be and is duty-bound obligations for children to take care of their elderly parents. Many families in China are inclined to this traditional way of old-age security, especially in rural areas[4]. Although Chinese old-age security in rural areas are explored continuously, the rural residents would prefer the traditional but the most reliable way of endowment they are familiar with in the fragmented endowment system in rural areas. With the changes in economic and social development, family endowment status has been shaken. With the gradual pilot of the new rural social endowment insurance, the concept of farmers' endowment has been quietly changed. But it is to be admitted that some farmers still have difficulties in breaking through the traditional concept and trying to accept the new endowment system. This deep-rooted endowment concept fundamentally hinders farmers to participate in the new rural social endowment insurance, which results in a very low participation rate in some areas. 


\section{B. The Income Level of Farmers}

The income level of farmers determines whether the farmers have economic ability to participate in the new rural social endowment insurance. The stronger the economic capacity of farmers is, the stronger their pension demands are and the weaker the economic capacity of farmers is, the weaker their pension demands are. In the rural families in China, their incomes are in very low levels, so the families are not rich enough to participate in the rural endowment insurance. Major sources of rural household's incomes includes net farm income, wage income and household sideline income, the incomes from these channels are relatively in a small quantity. According to the 2012 statistical bulletin published by the National Bureau of Statistics of China, it showed that in 2012 the annual net income per capita of rural residents was 7,917 yuan, much lower than that of the urban residents - 24,565 yuan[5]. Along with the price and other factors, the income of rural residents is hard for them to maintain a normal life. The new rural social endowment insurance system requires the insured rural residents to pay the insurance premiums, and there are five grades of payment for rural residents to choose. But the reality is that it is difficult for farmers to have the extra income to pay the premiums, even for payment in the lowest grade. After all, it is wise for a farmer to put their money to solve the practical problems rather than invest it for the future protection of life. Therefore, although new rural social endowment insurance is promoted for a while, farmers still show little interest in participating in the new rural endowment insurance since the income level of farmers is not so high, and there is also not much surplus funds.

\section{Farmers' Understanding and Satisfaction of the System}

With the vigorous promotion of the township government at all levels on the new rural social endowment insurance, the farmers has got a high degree of awareness of the new system, but they still can not know the specific policies deeply and thoroughly. As the new system is formed based on the old system, so some farmers feel confused on the old policy and the new one. They still thinks that insurance is just an accumulation of personal savings, and is of no benefits for themselves. Hereby, some farmers are not enthusiastic enough to participate in the new system. Only by letting farmers know that the new policy is implemented with the support of the central government, and letting them truly understand the specific terms of policy by advocacy, implementation steps and the benefits that they can get, can they not strongly reject, but actively participate in the new rural social endowment insurance. In addition, their satisfaction for the new rural social endowment insurance also affects the farmers' choices. Whether the new system takes into account the income level of farmers or not? whether it can protect the basic living needs for the elderly or not? whether the government and the collective provide a subsidy or not? and whether a subsidy amount is sufficient or not? These are the questions needed the government's first attention. Meanwhile, whether the implementation of policies and management mechanisms are sound or not, whether the fund is able to appreciate or not, whether the relevant legal system is perfect or not, these questions will affect farmers' evaluation ad satisfaction of the new system. When farmers can really understand the policy and are satisfied for it, their initiative and enthusiasm can be mobilized.

\section{Farmer' Confidence in the Government}

Various social works are organized and arranged constantly under the guidance of the government. As long as the government focus their attention, everything can be achieved. From the household contract responsibility system in 1980 , to the total abolition of agricultural taxes in 2006 , the government had done well in benefiting the farmers with its authority, and also established a good image in the minds of farmers. But the problems existing in the implementation of the new rural social endowment insurance pilot work directly affect the willingness of farmers insured. For the policy, given that the urban pension insurance ran through the problem of "empty accounts", the farmers still worry about the grants and subsidy from the central government; in terms of the personnel, whether the work of the village cadres are effective or not, whether the service from the staff in the insurance agencies is good or not; these are the questions farmers have been worrying about. As for the management regime in recent years, the fund embezzlement of social security occurred frequently in China, so the government's trust has been challenged [6]. Whether the government strengthen management or not, and whether the management system is sound or not, these are the factors the insured farmers consider. Therefore, if the government's implementation of the new rural social endowment insurance policy are in place, and all works are done properly, the farmers will be looking forward to the rural endowment insurance, and they will give much support for the new rural endowment insurance.

\section{E. Other Factors}

Besides these four factors, there are other factors that also affect the farmers' participation in the new rural social endowment insurance. Firstly, the education level of farmers. The higher the education level of farmers is, the stronger their ability to accept new things is. It will also be much more easy for the farmers to understand the substance as well as the benefits of the new policy. Secondly, the age. In rural areas, people who are in their 60 years old or above show a strong willingness to participate in the new rural social endowment insurance. Thirdly, the number of children in the family. Subject to the concept of "raising children for their old-age lives", if there are several sons in the whole family, the farmers will be unwilling to participate in the new rural social endowment insurance. Fourthly, the neighborhood. The author believes that this is a very subtle but great impact factor. In Chinese rural society, the farmers will have a certain herd and cluster characteristics, due to the low level of education, the low level of self-awareness, the kinship and "special trust" on the village. Their participation in the new rural social 
endowment insurance will be influenced by the behavior of the surrounding people and the impact of this invisible influence should not be underestimated in decision-making of the insured farmers[7].

\section{Conclusion}

The Chinese new rural social endowment insurance is a major agricultural policy, and its establishment is of great significance to shorten the urban-rural gap and safeguard the social fairness and stability. Whether the pilot of the policy is able to successfully promoted or not is related to the vital interests of farmers. This paper applies the food chain theory in ecology to the rural social endowment insurance to tease out an ecological chain from the factors affecting farmers' participation to the rapid development of the new rural social endowment insurance. With the analysis on the ecological theory and the reality, it showed that low-class nutrients factors affecting farmers' participation is extremely important to promote the development of the nutrients in next level. So, the government, as the leader of the new rural social endowment insurance should consider the following suggestions in order to ensure a positive force for low nutrients. Firstly: the government should optimize and innovate the design of the new rural endowment insurance system, increase the attractiveness of the farmers to the policy and modify and improve the corresponding rules and terms of policy in line with the reality of Chinese current situation in rural areas. Secondly: the government should increase the propaganda on new rural social endowment insurance through radio, television, pamphlets and other channels. On the one hand, it can help the farmers to change the traditional concept of family pension; on the one hand, it can allow farmers to understand the specific content of policies and the benefits brought hence. Thirdly: the government should increase financial support gradually, increase the amount of subsidy, as well as improve the relevant management system to prevent corruption and misappropriation of funds. In addition, it is time to improve service in the relevant authorities, and speed up the training of management personnel for the new rural social endowment insurance, which should also become one of the priorities for government's work in the future. Fourthly: the government should attach importance to the feature of the "social acquaintance" in the rural areas, and form a good reputation to lead other farmers to participate in the new rural social endowment insurance through a typical demonstration way. Finally: it should also improve legislation and strengthen the construction of the legal system in new rural social endowment insurance, so that the farmers can have a sense of security and involve in it actively.In short, there is still a long way to go to establish and improve the new rural social endowment insurance system. The whole society should be actively concerned about the rural endowment career, and jointly promote the healthy and harmonious development of the new rural social endowment insurance.

\section{Acknowledgment}

I would like to express my deepest thanks to professor $\mathrm{Li}$ Wang. With her guidence and support, I have finished this paper. Her attitude towards work and the persistent quest of the mind of science have influenced me a lot. I have also learned a lot from her, such as the spirit of hard-working and her warm heart. At last, please accept my sincere thanks for her help, which I will never forget.

\section{References}

[1] Http://www.gov.cn/zwgk/2009-09/04/content_1409216.htm, the State Council's guidance on carrying out the new rural social endowment insurance pilot, the website of the central people's government of the people's republic of china, 2009 -09-04.

[2] Jinjin Li, "Research on theory of enterprise ecological chain," Jilin University PhD thesis, 2011 (6).

[3] Guoru Hu, "Environmental protection," Beijing: China Environmental Science Press, 1993.

[4] Tingting Wang, "The development process and influencing factors of farmers' participating in the new rural social endowment insurance," Shandong University master's degree thesis, 2012 (11).

[5] Http://www.stats.gov.cn/tjgb/ndtjgb/qgndtjgb/t20130221_402874525.ht $\mathrm{m}$, the National Economic and Social Development Statistics Bulletin in 2012 in China, the website of National Bureau of Statistics of China, 2013-02-11.

[6] Huaizhong Mu \& Linlin Yan, "factors affecting farmers' participation in the new rural pension insurance," Population Research, 2012 (1).

[7] Dongkai Yang, "The research of farmers' willingness to participate new rural social endowment insurance and influencing factors," Huazhong Agricultural University master's degree thesis, 2002 (6). 